\section{O desafio da mudança: a transformação curricular de um Programa de Residência de Medicina de} Família e Comunidade

\author{
The challenge of change: the curricular transformation of Family \\ and Community Medicine Residency Program
}

El desafío del cambio: la transformación curricular de un

Programa de Residencia de Medicina de Familia y Comunidad

\section{Resumo}

Introdução: Um dos eixos centrais do Programa Mais Médicos para o Brasil prevê a reestruturação nas residências de Medicina de Família e Comunidade do país, de modo que elas estejam adequadas à nova legislação, sendo pré-requisito para as demais residências médicas do país. Para esta mudança, é necessário que os programas existentes adaptem os seus programas de modo que estes estejam em consonância com o que se espera de um Médico de Família e Comunidade. Objetivo: Analisar a experiência da Universidade Federal de Uberlândia e a metodologia utilizada na reforma curricular do Programa de Residência em Medicina de Família e Comunidade. Métodos: Estudo de caso com análise documental sobre o produto, atas e demais documentos construídos durante as três oficinas de reforma curricular executadas, além dos marcos regulatórios. Resultados: A metodologia utilizada nestas oficinas englobou o Arco de Maguerez como estratégia problematizadora que dialoga com a Pedagogia Progressista de Paulo Freire. Para participar das oficinas, foram convidados residentes, gestor, preceptores e docentes. Trabalhou-se com a matriz de planejamento estratégico Análise FOFA (Fortaleza, Oportunidade, Fraqueza e Ameaça) para realizar o diagnóstico situacional do programa; elencaram-se ainda os estágios a serem desenvolvidos, bem como os princípios pedagógicos utilizados e as ferramentas avaliativas. Conclusão: Observou-se uma mudança significativa no programa da residência com envolvimento principalmente de preceptores e residentes engajados na implementação desta nova proposta. Os desafios encontrados foram parcialmente superados, porém ainda existem questões relacionadas principalmente à dinâmica ensino-serviço que precisa ser melhor estruturada para a efetivação do novo programa.

Palavras-chave: Medicina de Família e Comunidade; Internato e Residência; Educação Médica

\author{
Natalia Madureira Ferreira ${ }^{a}$ \\ Gustavo Tenorio Cunha ${ }^{b}$ \\ Nicole Geovana Dias ${ }^{a}$
}

Como citar: Ferreira NM, Cunha GT, Dias NG. O desafio da mudança: a transformação curricular de um Programa de Residência de Medicina de Família e Comunidade. Rev Bras Med Fam Comunidade. 2018;13(40):1-12. http://dx.doi.org/10.5712/rbmfc13(40)1600
Fonte de financiamento: declaram não haver.

Parecer CEP:

1.627.889 (UFU), aprovado em 05/07/2016.

Conflito de interesses:

declaram não haver.

Procedência e revisão por pares:

revisado por pares.

Recebido em: 30/08/2017.

Aprovado em: 24/01/2018. 


\begin{abstract}
Introduction: One of the central axes provided by the Mais Médicos (More Doctors) Program to Brazil foresee the restructuring of Family and Community Medicine residencies in the country, so they could fit the new legislation, being a prerequisite for other medical residencies in the nation. For this change, existing programs need to tailor their programs so that they are in line with what is expected of a Family and Community Physician. Objective: To analyze the experience of the Federal University of Uberlândia and the methodology used in the curriculum reform of the Residency Program in Family and Community Medicine. Methods: Case Study with documental analysis about the product, minutes and other documents built during the three workshops of curriculum reform implemented, beyond the regulatory milestones. Results: The methodology used in these workshops embodied the Arch of Maguerez as a problematizing strategy that dialogues with the Progressive Pedagogy of Paulo Freire. In order to participate in the workshops, residents, managers, preceptors and teachers were invited. We worked with the strategic planning matrix Analysis SOWT (Strength, Opportunity, Weakness and Threat) to carry out the situational diagnosis of the program; the stages to be developed, as well as the pedagogical principles used and the evaluation tools were also mentioned. Conclusion: There was a significant change in the residency program, mainly involving preceptors and residents engaged in the implementation of this new proposal. The challenges encountered were partially overcome, but there are still issues related mainly to the teaching-service dynamics that needs to be better structured for the implementation of the new program.
\end{abstract}

Keywords: Family Practice; Internship and Residency; Education, Medical

\title{
Resumen
}

Introducción: Uno de los ejes centrales del Programa Mais Médicos para Brasil prevé la reestructuración de las residencias de Medicina de Familia y Comunidad en el país, de modo que ellas sean adecuadas a la nueva legislación, siendo requisito previo para acceder a las demás residencias médicas del país. Para este cambio, es necesaria una adaptación de los programas existentes para que estén en consonancia con lo que se espera de un Médico de Familia y Comunidad. Objetivo: Analizar la experiencia de la Universidade Federal de Uberlândia y la metodología utilizada en la reforma curricular del Programa de Residencia en Medicina de Familia y Comunidad. Métodos: Estudio de caso con análisis documental sobre el producto, actas y demás documentos construidos durante los tres talleres de reforma curricular ejecutados, además de los marcos regulatorios. Resultados: La metodología utilizada en estos talleres englobó el Arco de Maguerez como estrategia problematizadora que dialoga con la Pedagogía Progresista de Paulo Freire. Para los talleres fueron invitados residentes, gestores, preceptores y docentes y se trabajó con la matriz de planificación estratégica Análisis FODA (Fortaleza, Oportunidad, Debilidad y Amenaza), para realizar el diagnóstico situacional del programa, se enumeraron las etapas a ser desarrolladas así como los principios pedagógicos utilizados y las herramientas de evaluación. Conclusión: Se observó un cambio significativo en el programa de la residencia con envolvimiento principalmente de preceptores y residentes comprometidos en la implementación de esta nueva propuesta. Los desafíos encontrados fueron parcialmente superados, pero todavía existen cuestiones relacionadas principalmente con la dinámica enseñanza-servicio que necesita ser mejor estructurada para la efectuación del nuevo programa.

Palabras clave: Medicina Familiar y Comunitaria; Internado y Residencia; Educación Médica

\section{Introdução}

Em julho de 2013, é publicada medida provisória que institui o Programa Mais Médicos para o Brasil, abrangendo três esferas de atuação: autorização do funcionamento dos cursos privados de medicina que passa a ser realizado por meio de chamamento público; formação do médico no Brasil, que passa a contar obrigatoriamente com um segundo ciclo de formação exclusivo na atenção primária; e o provimento de médicos por edital em que podem se inscrever médicos brasileiros e médicos estrangeiros, além da cooperação internacional. ${ }^{1}$

Em outubro do mesmo ano, a medida provisória é transformada em lei e a regulamentação acerca da formação médica sofre algumas alterações: a obrigatoriedade do cumprimento de $30 \%$ da carga horária de dois anos do estágio supervisionado na atenção primária e nos serviços de urgência do SUS; a necessidade de que os programas de residência médica ofertem anualmente número de vagas equivalente ao número de egressos da graduação em medicina do ano anterior; a obrigatoriedade da conclusão do primeiro ano de residência em Medicina de Família e Comunidade (MFC) para ingresso nas residências de Pediatria, Ginecologia e Obstetrícia, Cirurgia Geral, Medicina Preventiva e Psiquiatria; e a necessidade de um ou dois anos (dependendo da regulamentação da Comissão Nacional de Residência Médica) concluídos do 
Programa de Residência Médica em Medicina de Família e Comunidade (PRMMFC) para ingresso nas outras residências médicas, excetuando-se as de acesso direto, com meta prevista para ser alcançada em 31 de dezembro de 2018. ${ }^{2}$

Essa reestruturação na formação médica, ao mesmo tempo em que valoriza sobremaneira a especialidade de Medicina de Família e Comunidade, lança um grande desafio para os programas de residência da área: adequar seus programas às especificidades exigidas pela Comissão Nacional de Residência Médica comportando um número muito maior de médicos residentes. Além disso, vale ponderar que os PRMMFC têm como cenário de prática prioritário a rede de atenção primária dos municípios onde estão instalados, o que necessariamente significa uma articulação entre o ensino e o serviço para que as metas sejam alcançadas.

É justamente dentro deste contexto que a necessidade de reestruturação dos PRMMFC se apresenta. Acompanhando as mudanças estruturais da Rede de Atenção à Saúde, com a priorização do cenário da Saúde da Família e impulsionada por mudanças no processo de formação do médico, tanto na graduação quanto na residência médica, é essencial que os programas se adaptem às novas necessidades apresentadas. Importante ressaltar que estas necessidades são reflexo de uma sincronicidade entre Ministérios da Saúde e da Educação, Comissão Nacional de Residência Médica (CNRM) e Sociedade Brasileira de Medicina de Família e Comunidade (SBMFC) expressa pela Resolução 01 de 2015 da CNRM. ${ }^{3,4}$

Dentro desta perspectiva, o presente estudo se coloca como uma, dentre as muitas possíveis estratégias para a consolidação de transformações estruturais nos PRMMFC, buscando um meio termo entre as novas necessidades regulamentadas e a realidade previamente existente dentro do contexto histórico-político da especialidade de Medicina de Família e Comunidade no Brasil.

\section{Métodos}

Este estudo é uma análise do processo de transformação curricular do PRMMFC da Universidade Federal de Uberlândia (UFU) frente à necessidade da instituição em adequar o seu respectivo programa aos novos marcos regulatórios, bem como qualificar o documento que norteia suas ações adequando-o às recomendações da SBMFC para a formação da especialidade.

Constituiu-se por meio de uma metodologia qualitativa de pesquisa o que, segundo Minayo, ${ }^{5}$ significa o desafio de criar teorias e instrumentos que se aproximem da suntuosidade que é a vida humana em sociedade, ainda que com suas muitas limitações. O percurso teórico-metodológico fundamenta-se no estudo de caso, que é um meio de organizar dados preservando no objeto estudado a sua característica unitária. ${ }^{6}$ Para Yin, ${ }^{7}$ o estudo de caso é mais apropriado para responder questões de "como" e "por que", além disso, assim como os experimentos, é generalizável às proposições teóricas e não às populações. A meta, neste sentido, não será a amostragem, mas a generalização de teorias (generalização analítica) que podem ser aplicadas em outros cenários.

Para a coleta de dados, foram utilizados: os documentos (plano de estágio, programa e instrumento avaliativo) previamente existentes do PRMMFC; atas e relatórios produzidos durante as oficinas de reestruturação curricular, realizadas entre dezembro de 2015 e fevereiro de 2016, e o Programa de Residência finalizado após a realização completa da intervenção. Foi realizada, então, uma análise 
documental que abarcou inclusive o Currículo Baseado em Competências da Sociedade Brasileira de Medicina de Família e Comunidade e a Resolução 01/2015 da CNRM.

Foram observados e seguidos todos padrões éticos (Normas e Diretrizes Regulamentadoras da Pesquisa Envolvendo Seres Humanos - Resolução CNS 196/96, II.4) da Declaração de Helsinki, com aprovação da pesquisa pelo Comitê de Ética em Pesquisa - parecer número 1.627 .889 e colhido o Consentimento Livre e Esclarecido dos Participantes que optaram em participar das oficinas.

\section{Resultados e discussão}

Para a transformação curricular, foram propostas três oficinas para as quais foram convidados residentes de MFC do primeiro e segundo ano, preceptores MFC dos estágios nas Unidades Básicas de Saúde da Família, docentes do Departamento de Saúde Coletiva (DESCO) da UFU e a coordenação da Atenção Primária do Município.

A proposta metodológica das três oficinas realizadas se baseou nos princípios do Arco de Maguerez como estratégia para a metodologia problematizadora, que seguem as seguintes características: 1 Partir da observação da realidade para a identificação de um problema; 2 - Refletir sobre os possíveis determinantes do problema e escolher os pontos-chave do estudo; 3 - Teorização sobre os pontos-chave; 4 - Elaboração de hipóteses de solução e 5 - Aplicação das hipóteses de solução à realidade. ${ }^{8}$ Desta maneira, essa metodologia estimula o pensamento crítico sobre os problemas concretos do cotidiano no intuito de transformação da realidade em que o indivíduo está inserido, permitindo, assim, a construção de uma educação crítica e reflexiva, na qual os atores da mudança curricular sejam parte integrante da transformação desejada.

O Arco de Maguerez dialoga com a Pedagogia Progressista de Paulo Freire ${ }^{9}$ em que a prática pedagógica é crítica e reflexiva e, além disso, é um ato de transformação social. Sendo assim, o processo pedagógico é um ato coletivo e os atores envolvidos (residentes, preceptores, gestores, docentes, etc.) precisam fazer parte da mudança, sentindo-se representados no produto final. Isto permite que todos sintam-se parte da transformação e responsabilizem-se pela sua consolidação, uma vez que os problemas encontrados no seu cotidiano que serão transformados. ${ }^{9}$

\section{Oficina 01 - Diagnóstico Situacional}

Utilizou-se o panorama sobe e desce como dinâmica inicial para elencar as percepções positivas e negativas acerca da residência. Esta ferramenta é uma técnica que objetiva identificar fatores motivadores (SOBE), e desmotivadores (DESCE), de participação/atuação em algum curso/cenário de trabalho/dentre outros, no qual post-its de duas cores diferentes são distribuídos aos participantes para que estes possam listar, a partir de suas experiências, fatores de motivação e desmotivação na participação ou execução de determinada ação/atividade. Esse método é muito útil, também, para comparação e avaliação de processos de ensinagem, ao dar parâmetros avaliativos iniciais e finais. ${ }^{10} \mathrm{~A}$ pergunta norteadora foi: o que te motiva e te desmotiva na residência? Observamos abaixo o produto desta atividade na primeira oficina (Quadro 1):

Após a conclusão da atividade, desenvolveu-se um planejamento participativo através da Matriz Análise FOFA. O nome FOFA é derivado da intersecção que é feita das FORÇAS, OPORTUNIDADES, 
Quadro 1. Panorama Sobe e Desce da Oficina 01.

\begin{tabular}{|ll|}
\hline SOBE & DESCE \\
\hline Troca de Saberes & Burocracia \\
Possibilidade de Aprender & Falta de compromisso \\
Muitas possibilidades & Pouca governabilidade \\
Aprendizado & Salário \\
Troca de experiências & Falta de preceptoria \\
Planejamento conjunto & Estágios "soltos" \\
Possibilidade de qualificar a rede e fazer inovações & Não concordância ou compreensão com o papel do residente \\
Estar em construção & Falta de projeto pedagógico \\
Espaços protegidos: Tenda Invertida/ Reunião Clínica & Pouca ênfase na comunidade e interssetorialidade \\
Agenda "Flexível" & Atraso no cronograma \\
Nova coordenação & Dificuldade pactuação entre SMS e Universidade \\
Mais preceptores & Meta \\
Médicos de Família como professores do DESCO & Infraestrutura - espaço físico pequeno na Unidade \\
Maior prática e autonomia - mais atendimentos quando & Gastos para estar na UBSF: alimentação, gasolina, etc. \\
comparada com outras residências & \\
Tempo de Estudo & Alcançar os objetivos de aprendizagem para MFC \\
Formação de novos especialistas em MFC & \\
\hline
\end{tabular}

FRAQUEZAS e AMEAÇAS com as quais a instituição/programa/equipe tem que lidar. Esta matriz cruza os cenários pra saber quais serão os objetivos estratégicos da instituição/equipe/programa com menor chance de falha. ${ }^{11}$ Quando definimos os cenários, eles são separados em: internos e externos. Os internos são aqueles influenciáveis pela instituição/programa/equipe: força - elementos da instituição considerados vantajosos e fraquezas - pontos da instituição que devem ser melhorados. Os externos são situações não influenciáveis pela instituição: ameaças - elementos que dificultarão a execução ou o sucesso do empreendimento e oportunidades - elementos apoiadores para alcançar o objetivo. Objetivos estratégicos são as ações necessárias para alcançar determinado resultado. ${ }^{11}$

A terceira e última etapa da primeira oficina, após a identificação do objetivo estratégico, seria a leitura dos novos marcos regulatórios da Residência de Medicina de Família e Comunidade, bem como os prazos estabelecidos para alcançar a proposta elencada na Lei do Mais Médicos ${ }^{12}$ e na Resolução 01 de 2015 da CNRM. ${ }^{2}$

Quando observamos a ata da primeira oficina realizada, percebemos que a introdução com o panorama sobe e desce foi suficiente para introduzir a discussão sobre fatores positivos e negativos da residência, auxiliando na elaboração das forças e fraquezas da matriz FOFA. Observou-se que devido às motivações e desmotivações estarem relacionadas a fatores internos da residência, a proposta de realização de avaliação dos fatores externos com o uso da metodologia FOFA foi descartada pelos participantes.

Outro dado interessante é que os participantes identificaram como fraqueza central ou nó crítico do programa a ausência de um perfil do egresso desta residência e propuseram a elaboração de uma "imagemobjetivo" ou a construção de um perfil ideal sobre o qual toda a construção pedagógica do currículo deveria estar estruturada. Esta etapa de construção da imagem-objetivo foi fundamental para que o delineamento do programa de residência fosse realizado seguindo um eixo norteador claro para todos os participantes da reforma curricular. Pode-se observar no quadro 2 a consolidação do perfil almejado: 
Quadro 2. Produto da Oficina 01 - Perfil Esperado do Médico de Família Egresso do PRMMFC/UFU.

Espera-se que ao término deste Programa de Residência em Medicina de Família o médico seja capaz de:

- Comprometer-se com a construção do Sistema Único de Saúde, compreendendo suas nuances, limitações e fortalezas;

- Pensar o indivíduo inserido em um contexto familiar, comunitário, social e histórico que influenciam diretamente sua condição de saúde, bem como sua qualidade de vida, entendendo que a clínica precisa ser ampliada para ser resolutiva;

- $\quad$ Trabalhar com equipes interprofissionais, tornando-se parte integrante da equipe, valorizando e respeitando as opiniões dos outros profissionais de saúde e compartilhe responsabilidades e decisões;

- Entender que o Brasil e o mundo, por apresentarem contextos e realidades diferentes, apresentam necessidades em saúde diferentes. Sabendo, assim, adaptar-se às necessidades e peculiaridades locorregionais e culturais, como territórios rurais, quilombolas, indígenas;

- Compreender a forma como são elaboradas e implementadas as políticas públicas de saúde e a si mesmo como agente construtor dessas políticas;

- $\quad$ Exercer continuamente a educação permanente, mantendo-se tecnicamente atualizado e disponível para implementar inovações tecnológicas (tecnologias leves, leves-duras e duras);

- Problematizar baseado em novas evidências, ocorrências ou divergências em relação à saúde da população. Pensando criticamente as atualizações científicas;

- Perceber que as políticas de equidade são uma ferramenta importante na garantia do acesso e da qualidade do atendimento a minorias populacionais, devendo estar preparado a dialogar e fortalecer a inclusão desses grupos no cuidado à saúde;

- Aplicar conhecimentos relativos a práticas integrativas e complementares, bem como instrumentos da educação popular nas atividades diárias.

Contribuições - A utilização de uma metodologia estruturada, que permitiu identificar os fatores motivadores e desmotivadores, possibilitou que os participantes tivessem clareza sobre aspectos positivos e negativos em relação ao tema abordado, direcionando e ampliando o olhar sobre o programa. A matriz FOFA foi também um ponto considerado facilitador, visto que permitiu que muitas das dificuldades encontradas no processo de planejamento fossem abordadas de maneira estruturada. Possivelmente pela sua estrutura visualmente simples, sem muitas etapas para elucidação, é uma ferramenta facilmente aplicável em planejamento de grupos.

Limites - O panorama sobe e desce deu margem para que cada participante inferisse sobre seu elemento motivador e desmotivador a partir do seu cenário. Isso trouxe uma variação na leitura da atividade, permitindo, ao mesmo tempo, que as pessoas fossem bem específicas ou bem genéricas, ressaltando a heterogeneidade do grupo. Outro limite da ferramenta é que alguns dos elementos do "desce" são informações sobre os quais o grupo não tem governabilidade e acabam se tornando "queixas sem solução", o que pode gerar frustrações ou sensação de "não ser ouvido" por parte dos participantes. Em relação à matriz FOFA, a presença de poucos membros externos (docentes, gestores, residentes de outros programas ou preceptores de outros estágios) ao programa prejudicou a elaboração das Oportunidades e Ameaças (fatores externos da matriz). No Quadro 3 observa-se o esquema da matriz FOFA produzida:

\section{Oficina 02 - Estágios}

Primeiro momento - discussão da relatoria realizada da oficina 01 encaminhada previamente por e-mail para ser aprovada. Discussão e aprofundamento teórico sobre a Lei do Mais Médicos, ${ }^{12}$ Resolução 01 de 2015 da CNRM² e Currículo Baseado em Competência da SBMFC. ${ }^{13}$ Segundo momento - destinado à discussão dos cenários de prática existentes (incluindo os objetivos pedagógicos e competências desenvolvidas em cada estágio), cenários de prática necessários para o desenvolvimento do perfil do 
Quadro 3. Produto da oficina 01 - Matriz FOFA.

\begin{tabular}{|ll|}
\hline Força (Ajuda - Fatores Internos) & Fraqueza (Atrapalha - Fatores Internos) \\
\hline $\begin{array}{l}\text { Tempo de supervisão dos residentes } \\
\text { Apoio do Departamento de Saúde Coletiva } \\
\text { Interesse dos residentes }\end{array}$ & $\begin{array}{l}\text { Pouco tempo para a residência por parte dos supervisores } \\
\text { Mudança do Currículo }\end{array}$ \\
$\begin{array}{l}\text { Pouco tempo destinado para a preceptoria } \\
\text { Nontão do estudante de graduação com o residente }\end{array}$ & $\begin{array}{l}\text { Pouca visibilidade/desconhecimento da residência } \\
\text { Ausência de Programa/Projeto da residência }\end{array}$ \\
\hline Oportunidades (Ajuda - Fatores Externos) & Falta de Clareza do Perfil do Egresso \\
\hline COAPES & Ameaças (Atrapalha - Fatores Externos) \\
Curso de Capacitação dos Preceptores & \\
\hline
\end{tabular}

médico de família egresso do programa e seleção de preceptores aptos para recepcionar o residente nestes cenários.

Na segunda oficina, a proposta metodológica foi adequada de acordo com o produto da primeira, de maneira que a proposta apresentada ao grupo foi de discussão dos marcos regulatórios da residência e estruturação dos estágios e cenários de prática baseado no documento Currículo Baseado em Competências da SBMFC. ${ }^{13}$ A proposta foi rejeitada, de modo que a avaliação dos estágios e cenários de prática já existentes foram discutidos, tendo como foco o perfil esperado do residente egresso.

Elemento que dificultou a resolutividade desta oficina foi a ausência de participantes da gestão municipal. A experiência individual de cada residente, bem como a avaliação subjetiva de preceptores, foi considerada nesta etapa, tendo como perspectiva as competências esperadas no desenvolvimento de cada estágio e o perfil de egresso desejado.

Contribuições - O respeito à decisão do grupo de não fazer aprofundamento teórico e/ou político no espaço foi importante para solidificar o caráter colaborativo e respeitoso do processo de transformação curricular, auxiliando principalmente no manejo de conflitos e na dissolução dos pontos de tensão. Outro fator importante foi abrir um espaço para avaliação e escuta das dificuldades que os residentes encontraram nos cenários de prática que existiam, bem como nas limitações dos preceptores envolvidos com processo formativo.

Estágios que não apresentavam objetivos pedagógicos claros e/ou preceptores que não compreendiam seu papel de mediador do conhecimento puderam ser expostos em um ambiente seguro. Não estava previsto, até o momento, espaços de avaliação, por parte dos preceptores e residentes, do programa ou mesmo da estrutura dos estágios. Permitir o diálogo com uma escuta amorosa e respeitosa foi fundamental para que todos colaborassem no sentido de efetivamente construir um programa que avançasse.

Limites - A ausência de uma metodologia estruturada para que a escuta pudesse ser mais objetiva e com critérios mais específicos. Não foi elaborado um documento ou instrumento que auxiliasse no processo avaliativo e, talvez por este motivo, muitas das queixas e avaliações negativas por parte dos residentes ficaram restritas a experiências pessoais. Além disso, um processo avaliativo regular e estruturado permitiria uma avaliação seriada e também formativa tanto do cenário quanto dos preceptores que ali atuam, possibilitando um feedback que qualificasse o serviço e o seu objetivo pedagógico. Outro limite importante foi a ausência de preceptores de outras especialidades para fazer o contraponto em relação à avaliação realizada pelos residentes. 


\section{Oficina 03 - Avaliação}

Discussão sobre avaliação formativa e apresentação de algumas metodologias avaliativas destinadas a estágio em serviço.

Na terceira e última oficina, após reavaliação da metodologia inicialmente desenhada, foi proposto ao grupo a leitura dos documentos regulatórios da residência, discussão de metodologias de avaliação de cenários de prática previamente selecionados e estruturação da metodologia avaliativa do programa de residência. A proposta foi aceita pelos participantes e foi feita a leitura dos documentos: Resolução 01 de 2015 da CNRM² e Currículo Baseado em Competência da SBMFC. ${ }^{13}$ Foram apresentadas, após a discussão dos documentos, as metodologias avaliativas que haviam sido propostas levando-se em conta a experiência em outros programas de residência de Medicina de Família do Brasil: preceptoria minuto, técnicas de feedback, avaliação 360, portfólio, Mini-CIEX, prova discursiva e múltipla escolha. ${ }^{14-19}$

Contribuições - A estruturação da metodologia avaliativa e a participação de preceptores e residentes neste processo contribuiu em muito para a compreensão dos mesmos sobre o que se espera de cada ator, bem como a percepção do processo formativo vinculado à proposta avaliativa. Além disso, o Currículo Baseado em Competências deixou claro a todos os participantes o que se espera que seja desenvolvido em cada estágio, permitindo para a supervisão, preceptoria e residentes um alinhamento em relação aos objetivos do estágio coerentes com as atividades desenvolvidas e a metodologia avaliativa utilizada.

Outro elemento importante é que grande parte dos participantes, à exceção dos docentes, não conhecia as metodologias propostas e precisaram se apropriar não somente das ferramentas em si, mas do que se pretende em relação à competência avaliada. É importante que o residente e o preceptor se empoderem sobre o processo avaliativo, de aprendizagem e sejam atores ativos de seu próprio aprender.

Limites - Apesar de bastante produtiva, a oficina não preparou uma metodologia para introduzir os conceitos abordados sobre avaliação. Equivocadamente, partiu-se do pressuposto de que os participantes já dominavam metodologias e uma compreensão acerca da avaliação. A apresentação dos métodos e seus objetivos poderia ter sido realizada com metodologias ativas que permitissem aos participantes construir seus próprios conceitos sobre processo avaliativo e a melhor metodologia a ser aplicada em cada cenário ou momento.

Apesar de todas as oficinas terem sido preparadas e sua metodologia pensada previamente, ter flexibilidade para adaptar metodologia e conteúdo às necessidades dos participantes foi essencial para a continuidade do trabalho. Podemos observar no Quadro 4 algumas das mudanças promovidas pela mudança curricular executada.

Observando as mudanças ocorridas no programa, percebemos uma maior aproximação com a realidade vivenciada na atenção primária. Grande parte dos cenários de prática, inclusive o que demanda atenção especializada, são realizados na rede municipal de saúde. Isso possibilita que o residente, além de vivenciar um serviço que dialoga diretamente com a realidade da atenção primária, possa experimentar os vários pontos da rede de atenção e com isso qualificar a gestão do cuidado. A utilização do Currículo Baseado em Competências da SBMFC como ferramenta norteadora para a estruturação dos planos de ensino dos estágios qualificou os objetivos do mesmo, bem como a proposta das atividades ali desenvolvidas. 
Quadro 4. Principais mudanças entre o antigo e o novo programa após a transformação curricular.

\begin{tabular}{|c|c|c|}
\hline & Antes da Transformação Curricular & Depois da Transformação Curricular \\
\hline Duração & 3 anos & 2 anos \\
\hline Cenários de Prática & $\begin{array}{ll}\text { Ambulatórios dentro do Hospital Clínicas da UFU de: } \\
\text { - } \quad \text { Ginecologia e Obstetrícia } \\
\text { - } \quad \text { Clínica Médica } \\
\text { - } \quad \text { Clínica Cirúrgica } \\
\text { - } \quad \text { Pediatria } \\
\text { - } \quad \text { Saúde Mental } \\
\quad \text { Saúde Coletiva (UBSF somente no R2) }\end{array}$ & $\begin{array}{l}\text { Acontece majoritariamente na UBSF com estágios } \\
\text { estratégicos em Saúde da Mulher, Saúde da } \\
\text { Criança, Saúde do Adulto, Saúde do Idoso, } \\
\text { Saúde Mental acontece prioritariamente na Rede } \\
\text { Municipal de Saúde }\end{array}$ \\
\hline Urgências/Emergência & $\begin{array}{l}\text { Realizado dentro do Pronto-Socorro do Hospital } \\
\text { de Clínicas da UFU }\end{array}$ & $\begin{array}{l}\text { Realizado nos serviços de Pronto-Atendimento da } \\
\text { Secretaria Municipal de Saúde }\end{array}$ \\
\hline Atendimento Especializado & $\begin{array}{l}\text { Realizado nos ambulatórios do Hospital de } \\
\text { Clínicas da UFU }\end{array}$ & $\begin{array}{l}\text { Acompanhamento do matriciamento realizado na } \\
\text { Rede municipal de Saúde e/ou ambulatórios da } \\
\text { atenção secundária do município }\end{array}$ \\
\hline Estágio Optativo & $\begin{array}{l}\text { No R2 (a partir da oferta da residência) e no R3 a } \\
\text { ser negociado entre preceptor e residente }\end{array}$ & $\begin{array}{l}\text { No R2 pactuado entre preceptor e residente de } \\
\text { acordo com as necessidades do residente e do } \\
\text { programa }\end{array}$ \\
\hline $\begin{array}{l}\text { Outras habilidades que } \\
\text { devem ser desenvolvidas }\end{array}$ & $\begin{array}{ll}\text { - } & \text { Preceptoria } \\
\text { - } & \text { Gestão } \\
\text { - } & \text { Epidemiologia } \\
\text { - } & \text { de maiorfeamento técnico em procedimentos } \\
& \text { de maidade no R3 }\end{array}$ & $\begin{array}{ll}\text { - } & \text { Incorporação da epidemiologia aplicada na } \\
\text { - } & \text { prática clínica } \\
\text { - } & \text { Iniciação à docência } \\
\text { - } & \text { Aperfão da clínica } \\
& \\
& \\
\text { acomento técnico ao longo do R1 e R2 }\end{array}$ \\
\hline Desenvolvimento Teórico & $\begin{array}{l}\text { Conteúdo extenso desenvolvido principalmente no } \\
\text { R1 e necessidade de entrega de artigo ao final do } \\
\text { programa }\end{array}$ & $\begin{array}{l}\text { Conteúdo teórico aplicado através de reuniões } \\
\text { clínicas com metodologia ativa e não há } \\
\text { necessidade de entrega de artigo para publicação }\end{array}$ \\
\hline UBSF e Preceptoria & $\begin{array}{l}\text { Volante: de maneira que o residente ficaria } \\
\text { rodiziando entre preceptores e UBSFs }\end{array}$ & $\begin{array}{l}\text { Residente fica vinculado a um preceptor e equipe } \\
\text { durante os dois anos }\end{array}$ \\
\hline Supervisão & $\begin{array}{l}\text { Introdução do mentoring/tutoria como estruturação } \\
\text { pedagógica para a supervisão }\end{array}$ & $\begin{array}{l}\text { Reuniões clínicas semanais com preceptores, } \\
\text { residentes e docentes; Tenda invertida semanal } \\
\text { realizada pelos docentes nas UBSFs e avaliação } \\
\text { realizada pelos docentes e preceptores }\end{array}$ \\
\hline Propostas inovadoras & $\begin{array}{l}\text { Estímulo à produção científica e desenvolvimento } \\
\text { de habilidades técnicas como radiologia e } \\
\text { cuidados paliativos }\end{array}$ & $\begin{array}{l}\text { - Estágio no ambulatório para população } \\
\text { transespecífica } \\
\text { - Implementação de Práticas Integrativas e } \\
\text { Complementares em Saúde nas atividades da } \\
\text { residência } \\
\text { - Estágio em Medicina Rural e com populações } \\
\text { vulneráveis (assentamentos) } \\
\text { - Estágio no Serviço de Referência a } \\
\text { Atendimento de Mulheres e Meninas Vítimas } \\
\text { de Violência Sexual }\end{array}$ \\
\hline
\end{tabular}

Isto deixa claro para preceptores e residentes o que se espera de cada um e qual a competência que o estágio precisa desenvolver, tornando as atividades e a metodologia avaliativa coerentes com os objetivos inicialmente propostos. Além disso, fica evidente para supervisores, preceptores, residentes e gestores qual o consenso da especialidade sobre a formação dos seus especialistas, norteando ações e pactuações com a rede municipal. Inclusive tornando claro para outras especialidades médicas e gestores municipais quais competências o MFC tem capacidade de realizar e que, portanto, podem ser incluídas na oferta da atenção primária municipal. 
Outro fator relevante é que o Currículo Baseado em Competências da SBMFC amplia o olhar institucional sobre a MFC, permitindo que outras especialidades e estudantes compreendam que esta residência desenvolve competências que não são adquiridas na graduação e que, portanto, não é uma junção de estágios nas diversas clínicas (Cirurgia, Médica, Ginecologia/Obstetrícia e Pediatria), mas que trabalha com um outro paradigma de cuidado.

Um elemento muito importante quando pensamos este processo de reforma curricular, que talvez tenha sido o decisório no sentido de operacionalizar as propostas e efetivar as mudanças, foi a presença de uma regulamentação nacional que orientasse o conteúdo da reforma e estabelecesse de maneira clara um prazo para a sua efetivação. Neste sentido a Lei do Mais Médicos e o marco regulatório da CNRM foram decisivos para que tudo o que foi construído pela equipe de reforma curricular pudesse ser aprovado nas instâncias deliberativas institucionais. Além disso, esta política nacional de incentivo à Atenção Primária através da Estratégia de Saúde da Família amplia em muito a capacidade de negociação da supervisão da residência com a rede de saúde do município.

A proposta do COAPES - Contratos Organizativos de Ação Pública Ensino-Saúde ${ }^{20}$ avança na tentativa de tornar a relação ensino-serviço menos susceptível tanto às mudanças, quanto às influências dos processos eleitorais. Apesar desta ferramenta importante na articulação macropolítica, a efetivação das transformações propostas acontecem no âmbito da micropolítica, das relações estabelecidas entre os diversos atores envolvidos (preceptores, residentes, equipe de saúde, supervisão da residência, coordenadores de distritos sanitários, etc). Desta maneira, quanto mais envolvidos no processo de gestão e construção do programa, mais integrados e alinhados estarão.

A reavaliação sistemática de um projeto pedagógico (programa, plano de ensino ou de estágio) possibilita ajustar o rumo e alicerçar o processo de aprendizagem em bases sólidas e coerentes. A transformação curricular deste programa era iminente e necessária, uma vez que estava defasado e assim possibilitava uma construção prática de estágios em desacordo com a legislação e incoerentes com os objetivos de aprendizagem. O exercício de repensar o projeto político pedagógico, estágios, avaliações e principalmente o perfil do egresso empoderou e ressignificou o trabalho com a residência para preceptores e supervisores.

Para os residentes, participar desta construção coletiva ampliou a compreensão pedagógica da formação em serviço e concedeu uma segurança norteadora sobre o seu processo de aprendizagem. Além disso, possibilitou que cada ator envolvido reavaliasse a sua participação e o seu trabalho com os residentes, qualificando cenários, preceptores e docentes.

Repensar a forma de fazer nos permite não somente mudar o que está ruim, mas também aprimorar e compartilhar boas experiências. A partir das oficinas, observou-se uma necessidade de aperfeiçoamento, por parte da preceptoria, sobre as práticas pedagógicas, desencadeando um curso de preceptoria para os profissionais da rede municipal de saúde envolvidos com a residência e com os estudantes de graduação do curso de medicina.

É fundamental, quando falamos em processo de ensino-aprendizagem, que haja uma sincronia entre o que se pensa dentro das instituições de ensino e o que se pratica no cotidiano das Unidades de Saúde. Realizar a aproximação com o serviço por meio do diálogo franco com preceptores, ouvindo, compartilhando e construindo em conjunto possibilitou um empoderamento por parte dos preceptores do 
que a eles era solicitado. Muitas vezes, não se discute as propostas pedagógicas, o que se espera do preceptor e não se dá um feedback sobre o trabalho que o mesmo vem desenvolvendo. Convidá-lo para construir o programa permitiu escutar e compartilhar, dentro dos limites de cada ator/cenário, descobrindo como fazer esta construção conjunta.

\section{Considerações finais}

Os PRMMFC têm um grande desafio pela frente para se adequarem à nova normatização e também para se ajustarem à ampliação proposta pela Lei do Mais Médicos. Esta expansão, embora necessária, precisa ser realizada com responsabilidade, garantindo a qualidade do ensino e da assistência para usuários do SUS e residentes de MFC. Para isso, entendemos ser fundamental que os programas estejam bem alicerçados em projetos político-pedagógicos coerentes e que a integração ensino-serviço-comunidade esteja bem alinhada para garantir a segurança do usuário e a aprendizagem do residente. Planejar esta mudança de maneira gradativa, iniciando com a reestruturação e/ou adequação dos programas de residência para depois ampliar, parece uma alternativa saudável para que equívocos não sejam perpetuados e magnificados com a expansão. Fazer este processo convidando os atores envolvidos, discutindo com preceptores e gestores a melhor maneira de fazer e utilizando uma metodologia estruturada mostrou-se um caminho inclusivo, empoderador e que compromete seus atores com a transformação planejada.

\section{Referências}

1. Brasil. Ministério da Saúde. Medida Provisória № 621 de 8 de julho de 2013. Institui o Programa Mais Médicos e dá outras providências. Brasília: Diário Oficial da União; 2013.

2. Brasil. Ministério da Educação. Secretaria de Educação Superior. CN de RM. Resolução 01 de 25 de maio de 2015. Regulamenta os requisitos mínimos dos programas de residência médica em Medicina Geral de Família e Comunidade - R1 e R2 e dá outras providências Brasilia: Diário Oficial da União; 2015.

3. Brasil. Ministério da Saúde. CN de RM. Resolução 01 de 03 de janeiro de 2016. Dispõe sobre a estrutura, organização e funcionamento das Comissões Estaduais de Residência Médica. Brasília: Diário Oficial da União; 2016.

4. Brasil. Ministério da Saúde. Programa mais Médicos - Dois Anos: Mais Saúde para os Brasileiros. Brasília: Ministério da Saúde; 2015.

5. Minayo MCDS. Análise qualitativa: teoria, passos e fidedignidade. Ciênc Saúde Coletiva.2012;17(3):621-6. DOI: http://dx.doi.org/10.1590/ S1413-81232012000300007

6. Ventura MM. Pedagogia Médica O Estudo de Caso como Modalidade de Pesquisa. Rev SOCERJ. 2007;20(5):383-6. [Internet]. [acesso 2018 Fev 2]. Disponível em: http://www.rbconline.org.br/wp-content/uploads/a2007_v20_n05_art10.pdf

7. Yin RK. Estudo de caso: planejamento e métodos. 5a ed. São Paulo: Bookman; 2010. 205 p.

8. Colombo AA, Berbel NAN. A Metodologia da Problematização com o Arco de Maguerez e sua relação com os saberes de professores. Semin Ciênc Sociais Hum. 2007;28(2):121-46. DOI: http://dx.doi.org/10.5433/1679-0383.2007v28n2p121

9. Freire P. Pedagogia da Autonomia: saberes necessários à prática educativa. 9a ed. São Paulo: Paz e Terra; 1997.

10. Mendonça ET, Cotta RMM, Lelis VP, Carvalho Junior PM. Paradigmas e tendências do ensino universitário: a metodologia da pesquisaação como estratégia de formação docente. Interface (Botucatu). 2015;19(53):373-86. [Internet]. [acesso 2018 Feb 2]. Disponível em: http://www.scielo.br/scielo.php?script=sci_arttext\&pid=S1414-32832015000200373\&lng=en\&nrm=iso\&tlng=pt

11. Cunha AS, Leite EB. Percepção ambiental: implicações para a educação ambiental. Sinapse Ambient. 2009;66-79. [Internet]. [acesso 2018 Fev 2]. Disponível em: http://www.pucminas.edu.br/graduacao/cursos/arquivos/ARE_ARQ_REVIS_ELETR20090930145741.pdf

12. Brasil. Ministério da Saúde. Lei № 12.871/2013 de 22 de outubro de 2013. Institui o Programa Mais Médicos, altera as Leis no 8.745, de 9 de dezembro de 1993, e no 6.932, de 7 de julho de 1981, e dá outras providências. Brasília: Diário Oficial da União; 2013. 
13. Sociedade Brasileira de Medicina de Família e Comunidade. Currículo Baseado em Competências para Medicina de Família e Comunidade. 2015;66-8. [acesso 2018 Fev 2]. Disponível em: http://www.sbmfc.org.br/media/Curriculo Baseado em Competencias(1).pdf

14. Neher JO, Gordon KC, Meyer B, Stevens N. A five-step “microskills” model of clinical teaching. J Am Board Fam Pract. 1992;5(4):419-24.

15. Chemello D, Manfrói WC, Machado CLB. O papel do preceptor no ensino médico e o modelo preceptoria em um minuto. Rev Bras Educ Med. 2009;33(4):664-9. [Internet]. [acesso 2018 Fev 2]. Disponível em: http://www.scielo.br/scielo.php?script=sci_arttext\&pid=S010055022009000400018\&lng=pt\&nrm=iso\&tlng=pt. DOI: http://dx.doi.org/10.1590/S0100-55022009000400018

16. Ende J. Feedback in clinical medical education. JAMA. 1983;250(6):777-81. [Internet]. [acesso 2018 Fev 2]. Disponível em: http://www. ncbi.nlm.nih.gov/pubmed/6876333. DOI: http://dx.doi.org/10.1001/jama.1983.03340060055026

17. Domingues RCL, Amaral E, Bicudo-Zeferino AM. Conceito global: um método de avaliação de competência clínica. Rev Bras Educ Med. 2009;33(1):148-51. [Internet]. [acesso 2018 Fev 2]. Disponível em: http://www.scielo.br/scielo.php?script=sci_arttext\&pid=S010055022009000100019\&lng=pt\&nrm=iso\&tlng=pt. DOI: http://dx.doi.org/10.1590/S0100-55022009000100019

18. Gomes AP, Arcuri MB, Cristel EC, Ribeiro RM, Souza LMBM, Siqueira-Batista R. Avaliação no Ensino Médico: o papel do portfólio nos currículos baseados em metodologias ativas. Rev Bras Educ Med. 2010;34(3):390-6. [Internet]. [acesso 2018 Fev 2]. Disponível em: http:// www.scielo.br/scielo.php?script=sci_arttext\&pid=S0100-55022010000300008\&lng=pt\&nrm=iso\&tlng=pt. DOI: http://dx.doi.org/10.1590/ S0100-55022010000300008

19. Norcini JJ, Blank LL, Duffy FD, Fortna GS. The mini-CEX: a method for assessing clinical skills. Ann Intern Med. 2003;138(6):476-81. [Internet]. [acesso 2018 Fev 2]. Disponível em: http://www.ncbi.nlm.nih.gov/pubmed/12639081. DOI: http://dx.doi.org/10.7326/00034819-138-6-200303180-00012

20. Brasil. Portaria Interministerial 1127 de 04 de agosto de 2015. Brasilia: Ministério da Educação/Ministério da Saúde; 2015. 